\title{
Ruptured intracranial aneurysms: the overall effect of treatment and the influence of patient selection and data presentation on the reported outcome
}

\author{
RS MAURICE-WILLIAMS, H MARSH \\ From the Royal Free Hospital and School of Medicine, London, UK
}

SUMMARY An attempt is made to assess the overall impact of current treatment of ruptured intracranial aneurysms, based on the outcome in 200 consecutive patients, unselected in that they were transferred to neurosurgical care as soon as they were referred, regardless of clinical condition. Overall mortality at 1 year was $35.5 \%$. It is estimated that at the present time treatment improves the one-year survival of patients who reach the primary care hospital by no more than $12-15 \%$. In assessing the apparent benefits of treatment, it is easy to overlook the effects of patient selection and the way in which data are presented. Other admission policies in line with current practice but involving greater selectivity and delay in transfer, could have reduced the one-year mortality of this series of patients to $16 \cdot 1 \%$, by excluding from neurosurgical care patients who were in a poor condition or about to deteriorate. The outcome data in this series could be presented in different ways so as to represent the surgical mortality as ranging between $13.8 \%$ and $3.3 \%$.

Accurate assessment of the benefits of high technology medicine is important. Recent series report major advances in the treatment of ruptured intracranial aneurysms, ${ }^{1-6}$ but it is easy to overestimate the overall impact of such treatment. Good results may reflect a careful selection of patients for admission and for surgery as well as improved technical expertise.

This article attempts to assess the effect of current treatment on the total population of patients with ruptured cerebral aneurysms, based on the outcome in 200 consecutive patients admitted under an "open door" admissions policy and treated by a single neurosurgeon. We have tried to show how the same outcome data can be presented in different ways so as to give differing impressions of the efficacy of treatment, and how the data would have been affected by different admissions policies.

Address for reprint requests: Mr RS Maurice-Williams, Royal Free Hospital, Pond Street, London NW3 2QG, UK.

Received 30 November 1984 and in revised form 7 May 1985. Accepted 10 May 1985

\section{Methods of treatment}

1 Admissions policy

Between July 1977 and December 1982 all patients under the age of $66 \mathrm{yr}$ referred to the senior author with a diagnosis of subarachnoid haemorrhage were transferred immediately, regardless of their clinical condition.

\section{Pre-operative treatment}

Hypotensive agents were not given. Of 200 patients with aneurysm, $171(85.5 \%)$ received antifibrinolytic therapy (tranexamic acid $6 \mathrm{~g} /$ day). Episodes of neurological deterioration diagnosed as being caused by cerebral ischaemia were treated with steroids, mannitol and plasma expanding agents.

\section{Timing of operation}

Patients in Hunt and Hess grades 1 and $2^{10}$ were not operated on within the first 7 days. Patients in grade 3 and 4 were not operated on until after 14 days and then only if their condition was stable. Three patients with intracranial haematoma causing cerebral compression underwent very early operation.

\section{Operation}

All operations were carried out by the first author. Intracranial operations were carried out using the microscope. Hypothermia was not used. During dissection of the aneurysms, the systolic blood pressure was lowered to between 70 and $90 \mathrm{~mm} \mathrm{Hg}$. 
Table 1 Time from presenting haemorrhage to neurosurgical admission

\begin{tabular}{lc}
\hline 24 hours or less & $106(53 \%)$ \\
Days $2-3$ & $34(17 \%)$ \\
$\Rightarrow \quad 4-7$ & $38(19 \%)$ \\
$\Rightarrow \quad 8-21$ & $20(10 \%)$ \\
\hline, $22-60$ & $2(1 \%)$ \\
\hline
\end{tabular}

\section{Post operative management}

Symptoms thought to be caused by cerebral ischaemia were treated with mannitol and plasma expanding agents and, in eight patients, with controlled hypertension.

\section{Follow up}

All patients have been followed up for at least one year.

\section{Results}

\section{Causes of subarachnoid haemorrhage}

During the period of the study, 292 patients with subarachnoid haemorrhage were admitted. Aneurysms were found in 200 patients $(68.5 \%)$ The first 80 of these were admitted to the Brook Hospital, the remaining 120 to the Royal Free Hospital. Causes of subarachnoid haemorrhage in the remaining cases were: arteriovenous malformations $25(8.6 \%)$ : no cause found $54(18.5 \%)$ : other causes 2 $(0.7 \%)$ (cerebral tumour, 1 moyamoya disease, 1$)$. Eleven patients $(3.8 \%)$ were not investigated, either because they were judged unfit or because they died before investigation and no necropsy was performed. Of the patients in whom no cause of bleeding was found, full cerebral angiography was performed in 48 , bilateral carotid angiography in six.

\section{Expected incidence of subarachnoid haemorrhage}

Over the period of the study, it was estimated that 347 patients with subarachnoid haemorrhage could have been expected to have been admitted to hospital within the catchment area. This figure is based on the following assumptions:

(1) That the mean daily catchment population was 620,000 . This is based on data supplied to the London Health Planning Consortium in $1980^{7}$ and allows for the fact that the first author's "firm" was not on take every day. Of course, this estimate of the catchment population is approximate. There will have been cross-boundary referrals to and from the catchment areas of adjacent units and many of these referrals will have been on a personal basis. Nevertheless such referrals will tend to cancel each other out to some extent, and the calculations of the London Health Planning Consortium took account of these patient flows. (2) That the incidence of subarachnoid haemorrhage

Table 2 Clinical grade on admission (Hunt and Hess)

\begin{tabular}{ll}
\hline Grade & \\
\hline 1 & $60(30 \%)$ \\
2 & $46(23 \%)$ \\
3 & $49(241 \%)$ \\
4 & $30(15 \%)$ \\
5 & $15(71 / 2 \%)$ \\
& 200 \\
\hline
\end{tabular}

in the population is 12 per 100,000 per year. Various studies in Northern Europe have produced figures from 8 to 16 per 100,000 per year, mainly towards the lower end of this range..$^{8}$ (3) That $15 \%$ of patients with subarachnoid haemorrhage die before reaching hospital. ${ }^{9}$

\section{Characteristics of patients with aneurysms}

Tables 1 and 2 show the time from the presenting haemorrhage to neurosurgical admission, and the clinical grade at the time of admission, according to the criteria of Hunt and Hess. ${ }^{10}$ Sex and age distribution and the sites of aneurysms were as would have been expected from previous studies.

\section{Type of operation}

One hundred and thirty patients underwent operations for the aneurysms which had bled. Of these 126 had intracranial operations (105 aneurysms clipped, 9 wrapped, 12 clippings of proximal arteries) and four had common carotid ligations. In addition 11 of the 130 patients had surgery for additional non-ruptured aneurysm, without any deaths or morbidity.

\section{Timing of operation/clinical grade at operation}

The timing of operation is shown in table 3 . At the time of operation 121 patients $(93.1 \%)$ were in grades 1 to 3 . Seven patients $(5.4 \%)$ were in grade 4 and two $(1.5 \%)$ were in grade 5 .

\section{Reasons for not operating}

Seventy patients did not undergo surgery. The reasons were: insufficient recovery from the effects of the presenting haemorrhage, 39 (many of these patients died soon after admission, often from rebleeds or secondary ischaemia): secondary deterioration, 16 ( 5 from rebleeds, 11 from ischaemia): aneurysm judged inoperable 10: unfitness on grounds of age, intercurrent disease or multiple aneurysms 4: refused operation 1 .

\section{Mortality}

For all patients with aneurysms this was $32 \%$ at 3 months, $35.5 \%(71 / 200)$ at one year. For patients who underwent surgery it was $9.2 \%$ at one month, $13.8 \%(18 / 130)$ at one year. The one year mortality of non-operated patients was $75.7 \%(53 / 70)$. Causes of death in the 53 non-operated patients who died were: effects of presenting haemorrhage, 21 , rebleeding in 18 , and secondary cerebral ischaemia, 14 . Of the 18 patients who died from rebleeds, 14 were considered to be unfit or unsuitable (that is, grade 3 or above within the first 14 days) for operation at the time of rebleeding, one had refused operation and only three died of rebleeds (on days 7,7 and 8) while in a good clinical

Table 3 Timing of operation

\begin{tabular}{lr}
\hline Days & \\
\hline $0-3$ & 3 \\
$4-7$ & 6 \\
$8-10$ & 29 \\
$11-14$ & 32 \\
$15+$ & 60 \\
Total & 130 \\
\hline
\end{tabular}


Table 4 Effect of admission policies

\begin{tabular}{|c|c|c|c|c|c|c|}
\hline & \multirow[t]{2}{*}{ No admitted } & \multirow{2}{*}{$\begin{array}{l}\text { No of operations } \\
\text { as \% of admissions }\end{array}$} & \multicolumn{2}{|c|}{ Management mortality } & \multicolumn{2}{|c|}{ Operative mortality } \\
\hline & & & 3 months & 1 year & 1 month & 1 year \\
\hline $\begin{array}{l}\text { Policy } 1 \\
\text { Policy } 2 \\
\text { Policy } 3 \\
\text { Policy } 4\end{array}$ & $\begin{array}{l}200 \\
162 \\
155 \\
143\end{array}$ & $\begin{array}{l}65 \% \\
76 \% \\
79 \% \\
83 \%\end{array}$ & $\begin{array}{l}32 \% \\
22.8 \% \\
17.4 \% \\
14 \%\end{array}$ & $\begin{array}{l}35.5 \% \\
24.1 \% \\
19.4 \% \\
16 \cdot 1 \%\end{array}$ & $\begin{array}{l}9.2 \% \\
7.3 \% \\
6.5 \% \\
5.9 \%\end{array}$ & $\begin{array}{l}13.8 \% \\
11.4 \% \\
10.6 \% \\
10.2 \%\end{array}$ \\
\hline
\end{tabular}

Table 5 Surgical mortality

\begin{tabular}{|c|c|c|c|}
\hline 1 & $\begin{array}{l}\text { All patients: at one month } \\
\text { at } 1 \text { year }\end{array}$ & $\begin{array}{l}12 / 130 \\
18 / 130\end{array}$ & $\begin{array}{l}(9.2 \%) \\
(13.8 \%)\end{array}$ \\
\hline 2 & $\begin{array}{c}\text { Grades } 1-3 \text { at operation: } \\
\text { at } 1 \text { month } \\
\text { at } 1 \text { year }\end{array}$ & $\begin{array}{r}9 / 121 \\
14 / 121\end{array}$ & $\begin{array}{l}(7 \cdot 4 \%) \\
(11.6 \%)\end{array}$ \\
\hline 3 & $\begin{array}{c}\text { Grades } 1-3 \text { at operation }(0 \\
\text { at } 1 \text { month } \\
\text { at } 1 \text { year }\end{array}$ & $\begin{array}{l}14 \text { days) } \\
2 / 60 \\
4 / 60\end{array}$ & $\begin{array}{l}(3 \cdot 3 \%) \\
(6 \cdot 6 \%)\end{array}$ \\
\hline
\end{tabular}

condition (grades 1-2) and awaiting operation.

8 Degree of disability of survivors

At one year this was as follows for 129 survivors. The outcome for the 112 survivors of surgery is shown in brackets:

No neurological deficit or disability $80.6 \%(89.3 \%)$ Mild neurological deficit but

independent

Moderate deficit/semi-independent

$5.4 \%(4.5 \%)$

$7.0 \%(3.6 \%)$

$7 \cdot 0 \%(2 \cdot 7 \%)$

9 Effect of different ways of presenting surgical mortality Surgical mortality could be considered at one month or one year: this for all patients or for those in a good/fair condition (grades 1-3) at the time of operation and for those operated on after 14 days, when the acute period of risk had passed. Different combinations of these variables yielded mortalities ranging from $13.8 \%$ at one year of all patients operated on to $3.3 \%$ at one month of 60 grade 1-3 patients operated on after 14 days. (table 5)

\section{The effect of different admission policies}

As the early day to day progress of all patients is known, it was possible to estimate what would have been the effect of different admission policies on the number of patients seen, the proportion operated on, and on the overall and surgical mortality, as shown in table 4 . The policies are hypothetical but policies 2 and 3 approximate to those operated by many units with non-acceptance of poor condition patients and delay in transfer until the patient's condition has stablised. Policy 4 approximates to the situation which would prevail in a tertiary referral centre, or in a service where patients were assessed by a visiting neurologist before transfer. The policies are:

(1) As here: all patients transferred as soon as referred regardless of clinical condition

(2) Grades 1-3 transferred as soon as referred, others transferred when/if they reach grade 3 .

(3) Grades 1-3 transferred on Day 4. Others when/if they reach grade 3 .

(4) Grades 1-3 transferred on Day 8. Other patients when/if they reach grade 3 .

\section{Discussion}

Rupture of an intracranial aneurysm is a grave condition. With conservative management over $60 \%$ of those who reach hospital alive die within a year."

The major causes of death are neurological damage inflicted by the presenting haemorrhage, cerebral ischaemia from delayed vasospasm and recurrent haemorrhage. ${ }^{211-13}$ Only rebleeding is prevented by surgical treatment of the aneurysm. Over the last $\mathbf{3 0}$ years, reported surgical mortality has fallen from over $25 \%$ to under $5 \% .^{1-3514-17}$ The introduction of microsurgical techniques and advances in neuroanaesthesia have contributed to this improvement.

However, reports of the outcome after surgery may give a misleading impression of the efficacy of treatment as patients who are operated on are a highly selected group. Poor condition patients and those with intercurrent disease who may be expected to do badly, may be judged to be unfit for surgery and hence be excluded from surgical series. Because of the disappointing results of early surgery, many neurosurgeons wait 10 days or more before operating and some additional patients will die or become unfit for surgery during this time. ${ }^{1} 1819$ Recent papers have pointed out that inclusion of all cases admitted under neurosurgical care, not just those selected for surgery, results in a "management mortality" that is very much higher than the "operative mortality" 2420 but little attention has been paid to the fact that not all cases reach the neurosurgeon.

Our admission policy, which was designed to establish a very close working relationship with the physicians in the primary care hospitals of our catchment area, is unusual. It results in more cases of subarachnoid haemorrhage being admitted to neurosurgical care, but has the disadvantage of placing a heavy load on the neurosurgical beds available. 
Few neurosurgeons admit all cases of subarachnoid haemorrhage as soon as they are referred. Poor condition patients may not be admitted at all while it is often the practice to allow a few days for the patient's condition to stabilise before he is transferred. Long delays may occur where units accept patients from great distances and from overseas. As a consequence many patients will die or deteriorate before they are transferred to neurosurgical care. Even in the present series, where all patients under the age of $65 \mathrm{yr}$ were transferred immediately they were referred, $30 \%$ arrived after 72 hours. Patients referred late had generally had mild bleeds which resulted in delay in diagnosis. The 292 patients with subarachnoid haemorrhage represented $84 \%$ of the 347 cases which it was calculated would have been admitted to hosptial in the catchment area over the same period of time. A further $10 \%$ would have been accounted for by patients aged over $65 \mathrm{yr}$ who were not accepted, leaving about $5 \%$ who were admitted to hospital but not referred.

As the early day to day progress of all the patients was known, it was possible to estimate the effect of three further admission policies which approximated to other current practices. With increasing selectivity and more delay before transfer, the one year total mortality would have been reduced from $35.5 \%$ to $16.1 \%$ and the one month surgical mortality from $9.2 \%$ to $5.9 \%$. Fewer patients would have been admitted but the proportion undergoing surgery would have risen.

Even in a given series, the outcome data may be presented in different ways, which give different impressions of the results of treatment. Surgical mortality is commonly taken to refer to deaths within one month of operation, though deaths attributable to the effects of surgery may occur after this time. Mortality may be considered for all patients undergoing surgery, or just for those in a good or fair condition (grades 1-3) at the time of operation. High risk patients operated on in the acute phase may be excluded. By these means the "surgical mortality" in this series can be varied between an upper figure of $\mathbf{1 3 . 8 \%}$ at one year (all cases) to $3.3 \%$ at one month for patients in grades 1-3 who were operated on after the acute phase (table 5). The latter figure is in line with current published results, suggesting that the outcome in this series is probably not unrepresentative. None of these figures is incorrect but no single one gives the complete picture.

Tables constructed by Alvord allow one to predict the survival of a given ruptured aneurysm population without surgical treatment for any period between one month and 2 years if for each patient two variables are known: the clinical grade and the time that has elapsed since the presenting haemorrhage. ${ }^{21}$ If the Alvord tables are applied to this series, the predicted one year survival without surgical treatment would have been $57.5 \%$. The actual one year survival of $64.5 \%$ represents an increase of $7 \%$, or to put it in another way, an increase of actual survivors over expected survivors of $12 \%$. The one sided probability of this degree of improvement occurring by chance is $\mathbf{0 . 0 2}$. If the one month mortality after surgery of patients in grades 1-3 at the time of operation had been only $3 \%$, as low a figure as any that has been reported, the one year survival would have been improved by only $15 \%$. It must be pointed out that Alvord's figures for survival without surgical treatment are based on the outcome of series of 15-20 years ago. It is possible that improved non-surgical modes of treatment have improved the prospects of the conservatively treated patient since that time.

It is of course possible that a different management scheme might have led to a better overall outcome. For instance, the use of antifibrinolytic treatment in the majority of our patients may have had some influence on the results. In this series, surgery was deliberately delayed for 7-10 days or more, for most patients. Recently there has been renewed interest in very early surgery ${ }^{22-24}$ It is argued that a higher surgical mortality will be more than balanced by patients saved from death from rebleeding. It has even been suggested that delayed ischaemia might be aborted by removal of subarachnoid clot at the time that the aneurysm is clipped. ${ }^{24}$ However, only three of our patients who were in a good or fair condition died from rebleeding whilst awaiting surgery. Early surgery might have saved these, but could well have led to the deaths of others. On balance, we believe that it is unlikely that earlier operation would have produced much improvement of the overall results.

A $12-15 \%$ improvement in the one year survival produced by neurosurgical treatment seems disappointing. Furthermore it only refers to those patients who reached neurosurgical care and were diagnosed as having aneurysms. It does not cover all the patients with aneurysms who reached hospital. It takes no account of patients with aneurysms who may have died amongst the estimated $5 \%$ of patients with subarachnoid haemorrhage who reached hospital but were not referred or amongst the $3.8 \%$ of patients with subarachnoid haemorrhage who were referred but not investigated. To a large extent the limited improvement in survival produced by treatment reflects the fact that many patients die from causes other than rebleeding and hence will not be saved by neurosurgical treatment. Nevertheless this way of presenting the outcome of 
treatment may allow a more valid assessment of the impact of medical and surgical care than do the results of surgery carried out on a highly selected group of patients. Attempts to compare the results of different centres with different admission and management policies will always be problematical and often positively misleading.

We thank Mr M Sharr for providing follow up information on some of the patients admitted to the Brook Hospital.

\section{References}

1 Yoshimoto T, Uchida K, Kaneko U, Kayama T, Suzuki J. An analysis of follow up results of 1000 intracranial saccular aneurysms with definitive surgical treatment. J Neurosurg 1979;50:152-7.

${ }^{2}$ Mullan S, Hanlon K, Brown F. Management of 136 consecutive supratentorial berry aneurysms. J Neurosurg 1978;49:794-804.

${ }^{3}$ Fox JL. Intracranial aneurysms. New York: SpringerVerlag, 1983.

${ }^{4}$ Ropper AM, Zervas NT. Outcome 1 year after SAH from cerebral aneurysm. J Neurosurg 1984;60:90915.

s Sundt TM, Koyabashi S, Fode NC, Whisnant JP. Results and complications of surgical management of 809 intracranial aneurysms in 722 cases. $J$ Neurosurg 1982;56:753-65.

- Nornes H, Wikeby P. Results of microsurgical management of intracranial aneurysms. $J$ Neurosurg 1979; 51:608-14.

${ }^{7}$ Report of the Study Group on Neurology and Neurosurgery. London Health Planning Consortium, 1980.

${ }^{8}$ Gudmundsson G. Primary subarachnoid haemorrhage in Iceland. Stroke 1973;4:764-7.

9 Crawford MD, Sarner M. Ruptured intracranial aneurysm-community study. Lancet $1965 ; 2: 1254-7$.

${ }^{10}$ Hunt WE, Hess RM. Surgical risk as related to time of intervention in the repair of intracranial aneurysms. $J$
Neurosurg 1968;28:14-19.

" Locksley HB. Natural history of subarachnoid haemorrhage, intracranial aneurysms and arteriovenous malformations. J Neurosurg 1966;25:321-68.

12 Allcock JM, Drake CG. Ruptured intracranial aneurysms: the role of arterial spasm. J Neurosurg 1965;22:21-9.

${ }^{13}$ Maurice-Williams RS. Ruptured intracranial aneurysms: has the incidence of early rebleeding been overestimated? J Neurol Neurosurg Psychiatry 1982; 45:774-9.

${ }^{14}$ Krayenbuhl HA, Yasargil MG, Flamm ES, Tew JM. Microsurgical treatment of intracranial saccular aneurysms. J Neurosurg 1972;37:678-86.

${ }^{15}$ Davis E. Subarachnoid haemorrhage. Med J Aust 1967;2:12-14.

${ }^{16}$ Post KD, Flamm ES, Goodgold A, Ransohoff J. Ruptured intracranial aneurysms. Case morbidity and mortality. J Neurosurg 1977;46:290-5.

${ }^{17}$ McKissock W, Richardson A, Walsh L. Middle Cerebral aneurysms. Lancet 1962;2:417-22.

${ }^{18}$ Mullan S. The initial medical management of ruptured intracranial aneurysms. In: Current Controversies in Neurosurgery. Philadelphia: WB Saunders Co. 1976:259-69.

19 Adams CBT, Loach AB, O'Laoire SAO. Intracranial Aneurysms - analysis of results of microneurosurgery. Br Med J 1976;2:607-9.

${ }^{20}$ Ljunggren B, Brandt L, Sundbarg G, Saveland H, Cronqvist S, Stridbeck H. Early management of aneurysmal subarachnoid haemorrhage. Neurosurgery 1982;11:412-18.

${ }^{21}$ Alvord EC, Loeser JD, Bailey WL, Copass MK. Subarachnoid haemorrhage due to ruptured aneurysms. A simple method of estimating prognosis. Arch Neurol 1972;27:273-84.

${ }^{22}$ Hugenholtz $H$. Elgie RG. Considerations in early surgery on good-risk patients with ruptured intracranial aneurysms. J Neurosurg 1982;56:180-5.

${ }^{23}$ Ljunggren B, Brandt L, Kagstrom E, Sundbarg G. Results of early operations for ruptured aneurysms. $J$ Neurosurg 1981;54:473-9.

${ }^{24}$ Kassell NF, Adams HP, Torner JC, Sahs AL, Taneda M. Effect of early operation for ruptured aneurysms on prevention of delayed ischemic symptoms. $J$ Neurosurg 1982;57:622-8. 